\title{
On The Control of Project Cost in the Investment Decision Stage Hongwe $\mathrm{Li}^{1}$ \\ ${ }^{1}$ University of Science and Technology Liaoning, Anshan Liaoning 114051, China aszxk@126.com
}

\begin{abstract}
Keywords: Investment estimate, Investment decisions,Project Cost ,Cost control
Abstract. In terms of the actual investment estimate, the construction plan is to control the actual cost of investment decisions, and other follow-up work, investment decision stage, construction plans, and other follow-up work, investment decision stage, construction plans, and other follow-up work, investment decision-making phase, construction plans, and other follow-up work, investment projects in the construction process, the construction process, the construction process. As high as 95\% 100\%, it shows the importance of the construction project investment decision-making stage cost control.
\end{abstract}

\section{Introduction}

With the construction industry as a pillar industry of the national economy at the same time, the construction project decision-making is not scientific, high consumption, low efficiency of the phenomenon, in the engineering construction project exists in the "unfinished project" and "three project", not only cause the waste of investment in the field of construction, interfere with the normal economic order, and economical society the construction idea. As everyone knows, the construction project is a system, the whole process of the system, from the project decision-making stage, design stage, construction stage until the completion of the final stage, each stage has different influence on the project cost in each stage, mutual influence, mutual restraint, mutual action. The cost of the investment decision-making stage control the construction project, not only to pay attention to the construction cost of construction, the construction project cost management in construction phase; but also pay attention to cost of the project, to be considered for future operating and maintenance costs, emphasizing the integrity and efficiency of the system of construction cost management of project cost, in line with international standards, the dynamic management of project cost.

The meaning of the construction project investment decision.

Project investment decision making is the process of choosing and deciding the investment action plan. It is the necessity and feasibility of the proposed project to carry out technical and economic demonstration, and the process of choosing the different construction schemes and making the judgment and decision.

The project investment decision-making is the criterion of the investment action, the correct project investment action is from the correct project investment decision-making. The project investment decision-making is correct or not, directly related to the success or failure of the project, the level of the project cost and investment effect. 
The correctness of the project decision is the premise of the rationality of the project cost.The project decision-making is correct, it means to make scientific decision, and in the premise of construction, optimize the best investment plan, achieve the reasonable allocation of resources, so as to reasonably estimate and calculate project cost, and effectively control the project cost, project decision-making error, the construction of the project, or the decision of the project, and can not make up.

The content of the project decision is the basis of the project cost.Project cost control throughout the whole process of project construction, but the decision-making stage of the technical and economic decision-making, the project cost has a major impact, especially the construction of the standard level, the selection of the construction site, process selection, equipment selection, etc., directly related to the high and low cost.Regardless of the cost management system, or from the perspective of investment, investment control, the decision-making phase of the project cost is not only necessary but also very important, can only be strengthened, not weakened.

Improve the investment decision-making phase of the project cost control procedures.Investment decision cost personnel must use the scientific method of budget, according to the relevant data collected data analysis and comparison and calculation, to ensure that the collection of data or data, detailed, accurate and reliable. Standard engineering project investment criteria, carefully do and construction projects related to the product and services market research, to grasp a large number of statistical data and information, comprehensive analysis and processing, demonstration of investment decision-making is correct, strengthen the investment budget. If the country can not reach the standard of economic benefit, the project will not be approved, and it will pay attention to the advanced nature of the project.

The economic evaluation of investment decision-making project is the key to control project cost.According to the relevant information, the pre construction project optimization scheme includes all technological schemes, engineering schemes, environmental plans, etc., can save the investment to $80 \%$, so that the real effective project cost is reasonable, economical investment cost should be focused on the construction project economic evaluation work, and according to the actual situation of the project, research, calculation and demonstration.

\section{Main contents of project cost management in decision making stage}

On the scale of the construction project.The reasonable construction scale of construction project is to choose the scale of production, production scale, low cost, large scale of production, low cost, and low economic benefit. Only reasonable determination of the scale of the construction project can ensure the rationality of the project investment and ensure the feasibility of the proposed project.

The determination of the level of construction standards.Construction standards can play a role in controlling the construction cost, the key lies in the standard level set is reasonable. The standard is too high, will be out of the actual situation and financial resources, the ability to bear the material, increase the cost, waste investment; construction standards set too low, will hinder technological progress, the impact of national economic development and the improvement of people's lives.

Reasonable choice of construction area and place. The choice of the construction area is reasonable or not, the fate of the proposed construction project, the impact of the project investment, the construction period is long, the construction quality is good or bad, but also affect the operation of the project.

The determination of the design scheme of the proposed project.The proposed project design includes the selection of process flow and selection of main equipment. The process must 
ensure that the product meets the requirements of the state, while the technology is advanced, the economy is reasonable, and the maximum increase of labor productivity and equipment utilization, and to protect the environment, ecological balance, save investment and reduce production cost, and seek the best economic and social benefits.

Investment estimation.Investment estimation is the most important factor in the investment decision-making stage, it is a special agency issued by the construction cost of the construction project, the calculation method, and other documents relating to the calculation of the project cost, is the project approval of the project proposal, the scale of the project planning. Only by reasonable estimate of the cost of the project investment, it can be used for engineering design and project implementation, reasonable, accurate or not, will affect the next stage of the design budget and construction plan budget, and when the feasibility study report is approved, the investment amount of the design task, not at random. The scope and depth of investment estimation should be estimated separately. The specific contents include: construction cost, equipment and working equipment purchase cost, installation cost, installation cost, other expenses, cost, construction period interest, fixed assets investment direction tax and working capital. The development of evaluation index should be in line with industry development policy.

\section{Methods and measures for effective control of project cost in the decision-making stage}

To establish a scientific decision-making system and to make reasonable investment estimation. The investment estimation is the basis of project economic evaluation, which is the basis of project economic evaluation, and the accuracy of investment estimation is the basis of project economic evaluation, and it is the basis of decision making, and the scientific decisionmaking system and decision-making system are the key to establish scientific decision-making system, so it is reasonable to estimate the investment.

Pay attention to the economic evaluation of construction projects.Mainly refers to the feasibility study and evaluation of the decision-making phase of the construction project, using the modern economic analysis method, to study the many economic factors of the proposed project, forecast, research, calculation and demonstration, comparison, the process of selecting the optimal scheme.

Construction project economic evaluation should do the following.

Dynamic analysis and static analysis are combined to dynamic analysis. Evaluation method to reflect the changes in the future period of time, consider the time factor of the funds, the value of the dynamic judgment.

Quantitative analysis and qualitative analysis to quantitative analysis. The basic requirement of economic evaluation is to evaluate the economic activity in the project construction and production process, and give a definite quantity concept. It should be emphasized that all the economic factors should be expressed in quantity.

The combination of forecast analysis and statistical analysis, in order to forecast analysis. The economic evaluation of the project should be based on the existing conditions, and to make a forecast of the amount of capital inflow and outflow time. Meanwhile, it is also to deal with some uncertain factors and risk factors, including sensitivity analysis, break even analysis and probability analysis.

The combination of macro and micro analysis and macro benefit analysis is the main. The economic evaluation of the project is divided into financial evaluation and national economic evaluation. When the enterprise's financial evaluation is feasible, and the national economic evaluation is not feasible, the conclusion of the national economic evaluation should be the main.

Combined with the benefit analysis of the whole process and the construction period, the benefit analysis of the whole process is mainly based on the benefit analysis of the whole process.Economic evaluation is to look at the entire calculation period, including the construction stage and the stage of production and operation of the whole process of economic benefits. Not only 
depends on how much the construction investment, duration, cost, but also the economic benefits after the project put into operation.

\section{Conclusion}

The cost control of construction project investment decision-making stage is very important for the whole project cost control, As the investment decision-making stage to affect the cost of many factors, so the cost control should be based on the owner and the project of various factors, and should not be isolated, only in this way can the project have accurate grasp and positioning, the most suitable investment decisions.

\section{References}

[1] Fang Li. Influence and measure of cost control in engineering design stage, China collective economy (3):16-19.2012.

[2] Jianzgong Shen. Cost control of real estate project design stage, Economy and management (16):80-82.2010.

[3] Xingpei Wu. Cost control and management of the whole process of construction project, Dam and safety (4):5-6.2009.

[4] Zengqian Lin. Problems and Countermeasures of the engineering cost management in design stage, Shanxi architecture (7):29-31.2014. 